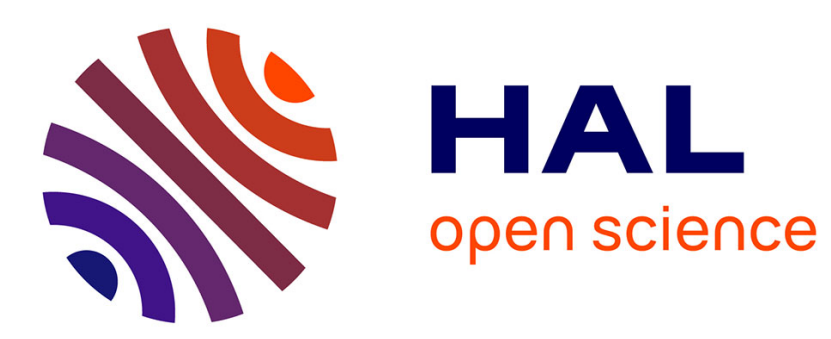

\title{
Calorimetric analysis of dissipative and thermoelastic effects associated with the fatigue behavior of steels
}

T. Boulanger, André Chrysochoos, C. Mabru, A. Galtier

\section{To cite this version:}

T. Boulanger, André Chrysochoos, C. Mabru, A. Galtier. Calorimetric analysis of dissipative and thermoelastic effects associated with the fatigue behavior of steels. International Journal of Fatigue, 2004, 26 (3), pp.221-229. 10.1016/S0142-1123(03)00171-3 . hal-03350366

\section{HAL Id: hal-03350366 https://hal.science/hal-03350366}

Submitted on 21 Sep 2021

HAL is a multi-disciplinary open access archive for the deposit and dissemination of scientific research documents, whether they are published or not. The documents may come from teaching and research institutions in France or abroad, or from public or private research centers.
L'archive ouverte pluridisciplinaire HAL, est destinée au dépôt et à la diffusion de documents scientifiques de niveau recherche, publiés ou non, émanant des établissements d'enseignement et de recherche français ou étrangers, des laboratoires publics ou privés. 


\title{
Calorimetric analysis of dissipative and thermoelastic effects associated with the fatigue behavior of steels
}

\author{
T. Boulanger ${ }^{\mathrm{a}, *}$, A. Chrysochoos ${ }^{\mathrm{a}}$, C. Mabru ${ }^{\mathrm{b}}$, A. Galtier ${ }^{\mathrm{c}}$ \\ ${ }^{a}$ Laboratoire de Mécanique et Génie Civil, UMR5508 Université Montpellier II CNRS, Place E. Bataillon, 34095 Montpellier cedex 05, France \\ ${ }^{\mathrm{b}}$ Département Génie Mécanique, Ecole Nationale Supérieure d'Ingénieurs de Constructions Aéronautiques, 1 Place Emile Blouin, \\ 31056 Toulouse cedex 05, France \\ ${ }^{\mathrm{c}}$ IRSID-ARCELOR Group, Voie Romaine B.P. 30320, 57283 Maizières-lès-Metz cedex, France
}

\begin{abstract}
The fatigue of dual phase steel was examined in terms of calorimetric effects in order to match the energy manifestations of fatigue and constitutive equations drawn up in a thermomechanical framework. A simplified method, assuming a homogeneous fatigue test, is proposed to determine heat source development from a temperature field provided by an infrared camera. Thermoelastic and dissipative sources were then separately identified. Experimental results concerning thermoelastic effects are in close agreement with theoretical estimates. Dissipation depends on the loading frequency and stress amplitude applied to the fatigue specimen. However, as the marked decrease in dissipation observed when testing a block at high stress was not easily interpretable in terms of material effects, we questioned the homogeneous fatigue test assumption.
\end{abstract}

Keywords: Fatigue; Steel; Infrared thermography; Thermomechanics; Dissipation

\section{Introduction}

Fatigue design is based on the conventional fatigue limit classically using statistical processing of numerous tests which are particularly time consuming and expensive for industrial applications.

To get a rapid estimate of the fatigue limit, several research teams have monitored increases in the mean temperature of fatigue specimens [1-4]. The slope change of the warming regime occurring within a certain loading range was empirically related to the fatigue limit corresponding to the chosen loading mode. Although realistic estimates of this limit are often obtained with some steel specimens, the method still generates questionable results $[5,6]$.

Another approach, using thermal data, consists of defining constitutive equations for the material and computing the temperature evolution due to fatigue mech-

\footnotetext{
${ }^{*}$ Corresponding author. Tel.: +33-4-67-14-34-83; fax: +33-4-6714-47-92.

E-mail address: boulanger@lmgc.univ-montp2.fr (T. Boulanger).
}

anisms [3,7]. The validity check of the chosen model is then based on a comparison between predicted and observed temperatures. The computations are based on the assumption of a homogeneous specimen and uniform mechanical fields.

Nevertheless, it could be problematic to consider specimen heating as a fatigue indicator inasmuch as temperature variations depend on the intensity and distribution of heat sources and also on heat diffusion within the material, and consequently on heat exchanges with the surroundings. This pattern was already noted in previous works during monotonous tests and oligocyclic loading at finite strain. In each situation, we developed an adapted infrared image processing procedure in order to deduce the distribution of heat sources intrinsic to the material behavior from thermal data. This approach was successfully used to track the development of localization zones (Lüders band propagation [8], martensite transformation front [9]).

In the case of fatigue behaviors of steels, data processing must separately estimate dissipated energy induced by micro-structural defects and thermoelastic coupling sources induced by reversible thermal expan- 
sion of the crystalline network. Our ultimate objective is currently to bridge the gap between energy manifestations and constitutive equations established in a thermomechanical framework. Coupling sources can be related to state equations, while dissipation data are associated with evolution equations. This thermomechanical approach should enhance the overall understanding and identification of the fatigue mechanisms in relation to micro-structure properties. It could also give rise to new criteria for material characterization and structure design. This paper focuses on the first step of this approach, which involves establishing a reliable energy balance, thus enabling a correct estimate of the different heat sources. The layout of the paper is as follows: Section 2 provides a brief review of the thermomechanical framework used to interpret our experiments; Section 3 discusses the different possible thermal models and presents the heat equation that we finally used to compute heat sources; Section 4 describes the experimental setup, the infrared device and the data processing; Section 5 gives some results.

\section{Thermomechanical framework}

From a mechanical point of view, we assume that fatigue tests can be described within the framework of quasi-static processes under the small perturbation hypothesis (SPH). Besides, concepts and results of classical thermodynamics of irreversible processes are used to establish the local heat equation $[10,11]$. Within such a thermomechanical framework, the equilibrium state of each volume material element is characterized by a set of $n$ state variables. The chosen state variables are: $T$, the absolute temperature, $\varepsilon$, the $\mathrm{SPH}$ strain tensor, and $\left(\alpha_{1}, \ldots, \alpha_{n-2}\right)$, the $n-2$ scalar components of the vector $\alpha$ of "internal" variables that sum up the microstructural state of the material. By construction, the thermodynamic potential is the Helmholtz free energy $\psi$.

Combining both first and second principles of thermodynamics provides the local heat Eq. (1):

$$
\begin{aligned}
& \rho C \dot{T}-\operatorname{div}(k: \operatorname{grad} T)=\left(\sigma-\rho \frac{\partial \psi}{\partial \varepsilon}\right): \dot{\varepsilon}-\rho \frac{\partial \psi}{\partial \alpha} \cdot \dot{\alpha} \\
& +\rho T \frac{\partial^{2} \psi}{\partial T \partial \varepsilon}: \dot{\varepsilon}+\rho T \frac{\partial^{2} \psi}{\partial T \partial \alpha} \cdot \dot{\alpha}+r_{\mathrm{e}}
\end{aligned}
$$

The left-hand term consists of a differential operator applied to the temperature, while the right-hand term groups the different heat sources [12]. Here, $\rho$ represents the mass density, $C$ the specific heat, $k$ the conduction tensor and $\sigma$ the Cauchy stress tensor. The different heat sources are in turn: the intrinsic dissipation $d_{1}=(\sigma-$ $\left.\rho \psi_{, \varepsilon}\right): \dot{\varepsilon}-\rho \psi_{, \alpha} \dot{\alpha}$, the thermoelastic source $s_{\text {the }}=$ $\rho T \psi_{, T \varepsilon} \dot{\varepsilon}$, , the "internal" coupling source $s_{\mathrm{ic}}=\rho T \psi_{, T \alpha} \cdot \dot{\alpha}$, and the external heat supply $r_{\mathrm{e}}$.
The following hypotheses were put forward for the infrared image processing to obtain the heat source estimate:

- Mass density and specific heat are material constants, independent of the thermodynamic state.

- Convective terms associated with the particular time derivative of the temperature are neglected because temperature gradients and displacement velocity amplitudes are low.

- The heat conduction tensor remains constant and isotropic during the test $\left(k_{\mathrm{ij}}=k \cdot \delta_{\mathrm{ij}}\right)$.

- The external heat supply $r_{\mathrm{e}}$ due to heat exchange by radiation is time-independent, so the equilibrium temperature field $T_{0}$ verifies:

$$
-\Delta T_{0}=r_{\mathrm{e}}
$$

- Temperature variations induced by the fatigue test have no influence on the micro-structural state. Naturally, this assertion becomes unsound as soon as the heat rises to a high level. Only small temperature variations will be considered in what follows. In such a context, the coupling source $s_{\text {ic }}$ is neglected in Eq. (1) and the fatigue is considered as a purely dissipative mechanism.

Under the above hypotheses, the heat conduction equation could be rewritten in the following compact form:

$\rho C \frac{\partial \theta}{\partial t}-k \Delta \theta=s$

where $\theta=T-T_{0}$ symbolizes the temperature variation, while $s$ stands for the overall heat source due to dissipation and thermoelastic effects. It is important to note that, although we have already assumed that there is no coupling between temperature and micro-structural variables, we did not specify the exact nature of these variables. Indeed, dissipation measurements are essential to identify irreversible phenomena and clarify the physical meaning of the variables $\left(\alpha_{1}, \ldots, \alpha_{n-2}\right)$. Once it is possible to determine reliable heat balances, a micro-structural model could be designed which accounts for energy phenomena.

\section{Simplified heat diffusion problems}

Determination of heat source fields within the whole gauge-part of the specimen should be an ultimate aim of image processing. Unfortunately, for 3D cases, this operation is an ill-posed inverse problem that is impossible to solve without information on the source distribution to be quantified [13]. However, for thin, flat specimens, several options may be proposed.

Let us denote $L, l$ and $e$ as the length, width and thick- 
ness, respectively, of the specimen gauge part. The associated coordinates are in turn $x, y$ and $z$.

\subsection{Two-dimensional diffusion problem}

The first option considers that the source averaged over the sample thickness is representative of what happens throughout the thickness. Integration of the heat equation according to this dimension then leads to a $2 \mathrm{D}$ diffusion problem. By denoting $\bar{f}(x, y, t)=$ $\frac{1}{e} \int_{-e / 2}^{+e / 2} f(x, y, z, t) \mathrm{d} z$ as the mean operation applied to $f$, we finally get:

$\rho C\left(\frac{\partial \bar{\theta}}{\partial t}+\frac{\bar{\theta}}{\tau_{\mathrm{th}}^{1 \mathrm{D}}}\right)-k\left(\frac{\partial^{2} \bar{\theta}}{\partial x^{2}}+\frac{\partial^{2} \bar{\theta}}{\partial y^{2}}\right)=\bar{s}$

where the approximation $\rho C\left(\bar{\theta} / \tau_{\mathrm{th}}^{1 \mathrm{D}}\right) \approx \frac{-k}{e}[\partial \theta / \partial z]_{-e / 2}^{+e / 2}$ claims linear uniform Fourier conditions at the specimen boundary. The time constant $\tau_{\mathrm{th}}^{1 \mathrm{D}}$ then characterizes heat losses through the specimen surfaces $z= \pm e / 2$.

In previous works [12,14], Eq. (4) was widely used to estimate $2 \mathrm{D}$ distribution of heat sources in monotonic or oligocyclic tests. To compute the differential operator, temperatures measured on the surface of the specimen were assumed to be very close to the average temperature field $\bar{\theta}(x, y, t)$. Then, since the thermal data were discrete and noisy, the differential operator was estimated by low-pass filtering and according to the properties of discrete Fourier transform and Fourier series. For fatigue tests, the signal-to-noise ratio and sampling rates are not good enough to compute relevant heat source distributions, as the 2D Laplacian operator is indeed a heavy noise amplifier. A second option can be chosen in such situations.

\subsection{One-dimensional diffusion problem}

To improve the signal-to-noise ratio and reduce the number of numerical space derivations, we may assume that the mean heat sources associated with each crosssection $S$ of the specimen is relevant for describing what happens throughout $S$. Integrating the heat conduction equation over the cross-section $S$ then leads to a 1D thermal diffusion problem. Indeed, by denoting

$\overline{\bar{f}}(x, t)=\frac{1}{S} \int_{-l / 2}^{+l / 2} \int_{-e / 2}^{+e / 2} f(x, y, z, t) \mathrm{d} z \mathrm{~d} y$

the heat equation becomes:

$\rho C\left(\frac{\partial \overline{\bar{\theta}}}{\partial t}+\frac{\overline{\bar{\theta}}}{\tau_{\mathrm{th}}^{2 \mathrm{D}}}\right)-k\left(\frac{\partial^{2} \overline{\bar{\theta}}}{\partial x^{2}}\right)=\overline{\bar{s}}$

The approximation $-k\left(\overline{\overline{\frac{\partial^{2} \theta}{\partial y^{2}}+\frac{\partial^{2} \theta}{\partial z^{2}}}}\right) \approx \rho C \frac{\overline{\bar{\theta}}}{\tau_{\mathrm{th}}^{2 \mathrm{D}}}$

is once more based on the assumption that heat losses at the cross-section boundary $(y= \pm l / 2, z= \pm e / 2)$ are linear with respect to the temperature variation $\theta$, with the heat exchange coefficient $h$ between the specimen and the surrounding air being constant:

$-k \operatorname{grad} \theta \cdot n=h \theta$

where $n$ is the unit vector normal to $S$.

To estimate the left-hand term of Eq. (5), thermo-profiles have to be built by averaging the temperature field over the specimen width. To make the method operational, these profiles are assumed to be close to the lengthwise temperature distribution $\overline{\bar{\theta}}(x, t)$. This method was successfully used to track specimen cross-sections where strain localization occurs [8].

\subsection{A simple differential equation for diffusion problems}

A third option can be formulated to further simplify Eq. (5). Like stress and strain fields, we may suppose that, before localization onset, the heat source distribution is uniform at any time within the specimen gauge part. This is consistent with a classical view of uniaxial tests. In such cases, the spectral solution of the heat equation can be analytically determined using eigenfunctions of the Laplacian operator. For symmetric linear boundary conditions and initial conditions corresponding to uniform temperature fields, the spectral solution may then be well approximated by considering only the first eigenfunction [12]. The heat equation can then be simplified as:

$\rho C\left(\frac{\mathrm{d} \theta}{\mathrm{d} t}+\frac{\theta}{\tau_{\mathrm{eq}}}\right) \approx s$

where $\theta$ is now the temperature variation at the center of the specimen gauge part, with $\tau_{\text {eq }}$ characterizing all local heat losses. This equation will be widely used hereafter to experimentally estimate the heat source, where $\theta$ being identified to the mean temperature of a small centered area, typically $2 \times 2 \mathrm{~mm}^{2}$.

\section{Experimental procedure}

\subsection{Setup and material}

The studied material is a dual phase steel (DP 60) provided by ARCELOR and frequently used in metal forming. DP60 is hot rolled steel grade containing ferrite and martensite. It is composed of $0.074 \mathrm{C}, 0.84 \mathrm{Mn}$, $0.038 \mathrm{P}, 0.002 \mathrm{~S}, 0.217 \mathrm{Si}, 0.04 \mathrm{Al}, 0.702 \mathrm{Cr}$, and 0.005 
Table 1

Thermophysical properties of DP60 steel grade

\begin{tabular}{llll}
\hline$\lambda\left(10^{6}{ }^{\circ} \mathrm{C}^{-1}\right)$ & $\rho\left(\mathrm{kg} \cdot \mathrm{m}^{-3}\right)$ & $C\left(\mathrm{~J} \cdot \mathrm{kg}^{-1} \cdot{ }^{\circ} \mathrm{C}^{-1}\right)$ & $\mathrm{k}\left(\mathrm{W} \cdot \mathrm{m}^{-1} \cdot{ }^{\circ} \mathrm{C}^{-1}\right)$ \\
\hline $10-11$ & 7800 & 460 & 64 \\
\hline
\end{tabular}

$\mathrm{N}$ (in wt.\%) [15]. The thermophysical properties are given in Table 1 . Table 2 presents the mechanical properties of DP60. All endurance limits $\Delta \sigma_{\mathrm{D}}$ were obtained at $2 \times 10^{6}$ cycles and are expressed in terms of stress range $\Delta \sigma$ for each stress ratio $R_{\sigma}=\sigma_{\text {min }} / \sigma_{\text {max }}$.

The fatigue machine used in the present work is a servo-hydraulic machine with a load cell of $\pm 25 \mathrm{kN}$. Tests were conducted on thin, flat specimens which have been designed to optimize the loading capacity of the testing machine at a maximum loading frequency $\left(\max \left(f_{L}\right)=50 \mathrm{~Hz}\right)$. The size of the gauge part of these specimens is $2.5 \times 10 \times 10 \mathrm{~mm}^{3}$.

Thermography detection was performed using a CCD infrared camera (Cedip SW). During the tests, the lens axis of the camera was kept fixed and perpendicular to the surface of the specimen. The maximum frame-rate of the IR camera reached 250 images per second (i.e. maximum sampling frequency $\left.\max \left(f_{S}\right)=250 \mathrm{~Hz}\right)$ for an image resolution of $64 \times 128$ pixels. This corresponds to a space resolution of about $0.2 \mathrm{~mm} /$ pixel which enables us to observe the whole gauge part of the specimen.

\subsection{Testing}

Within the above-mentioned limits imposed by the specimen geometry and machine capacity, it was possible to carry out load-control fatigue tests near the fatigue limit for two load ratios, $R_{\sigma}=0$ and $R_{\sigma}=-1$, with the loading path being a pure sine until $50 \mathrm{~Hz}$.

The fatigue tests were set up in blocks of a limited number of cycles, compatible with the finite RAM capacities of the IR device as regards the maximum number of recorded images and time necessary to download these infrared images. Each block consisted of 20,000 cycles performed at constant loading frequency $f_{\mathrm{L}}$, constant load ratio $R_{\sigma}$, and constant stress range $\Delta \sigma$. At the end of each block, the recorder of the infrared camera was switched off and the testing machine

Table 2

Mechanical properties of DP60 steel grade

\begin{tabular}{|c|c|c|c|c|c|}
\hline $\begin{array}{l}E \\
(\mathrm{MPa})\end{array}$ & $\begin{array}{l}R_{\mathrm{p} 0.2} \\
(\mathrm{MPa})\end{array}$ & $\begin{array}{l}R_{\mathrm{p} 0.02} \\
(\mathrm{MPa})\end{array}$ & $\begin{array}{l}R_{\mathrm{m}} \\
(\mathrm{MPa})\end{array}$ & $\begin{array}{l}\Delta \sigma_{\mathrm{D}} \\
(\mathrm{MPA}) \\
R_{\sigma}=0\end{array}$ & $\begin{array}{l}\Delta \sigma_{\mathrm{D}} \\
(\mathrm{MPa}) \\
R_{\sigma}=-1\end{array}$ \\
\hline 213000 & 401 & 360 & 611 & $464 \pm 15^{\mathrm{a}}$ & $526 \pm 5^{\mathrm{a}}$ \\
\hline
\end{tabular}

\footnotetext{
a Standard deviation.
}

stopped. Between two blocks, we waited about 10 min in order to restart at thermal equilibrium. For a single specimen, the range $\Delta \sigma$ may vary between blocks. For example, the basic diagram in Fig. 1 shows a steadily increasing stress range.

\subsection{Analysis of temperature variations}

For homogeneous uniaxial tests and according to Eq. (7), temperature variations induced by thermoelastic coupling and dissipation must conform to:

$\rho C\left(\frac{\mathrm{d} \theta}{\mathrm{d} t}+\frac{\theta}{\tau_{\mathrm{eq}}}\right)=s_{\text {the }}+d_{1}$

The linearity of Eq. (8) enabled us to separately study the respective influence of both sources on the temperature pattern. We then defined $\theta_{\text {the }}$ and $\theta_{\mathrm{d}}$ induced by $s_{\text {the }}$ and $d_{1}$, respectively.

\subsubsection{Thermoelastic coupling source}

The thermoelastic behavior is assumed to be linear and isotropic. Close to thermal equilibrium $\left(\theta \ll T_{0}\right)$ and for uniaxial tests, the volume thermoelastic source can be approximated by [11]:

$s_{\mathrm{the}} \approx-\lambda T_{0}(\dot{\sigma}+\lambda E \dot{\theta})$

where $\sigma$ denotes the tensile stress, $E$ Young's modulus and $\lambda$ the linear thermal expansion coefficient. With data in Tables 1 and 2 giving a small ratio of $T_{0} E \lambda^{2} / \rho C$ compared with $1\left(\approx 1.7 \times 10^{-3}\right)$, Eq. (8) may be simplified as:

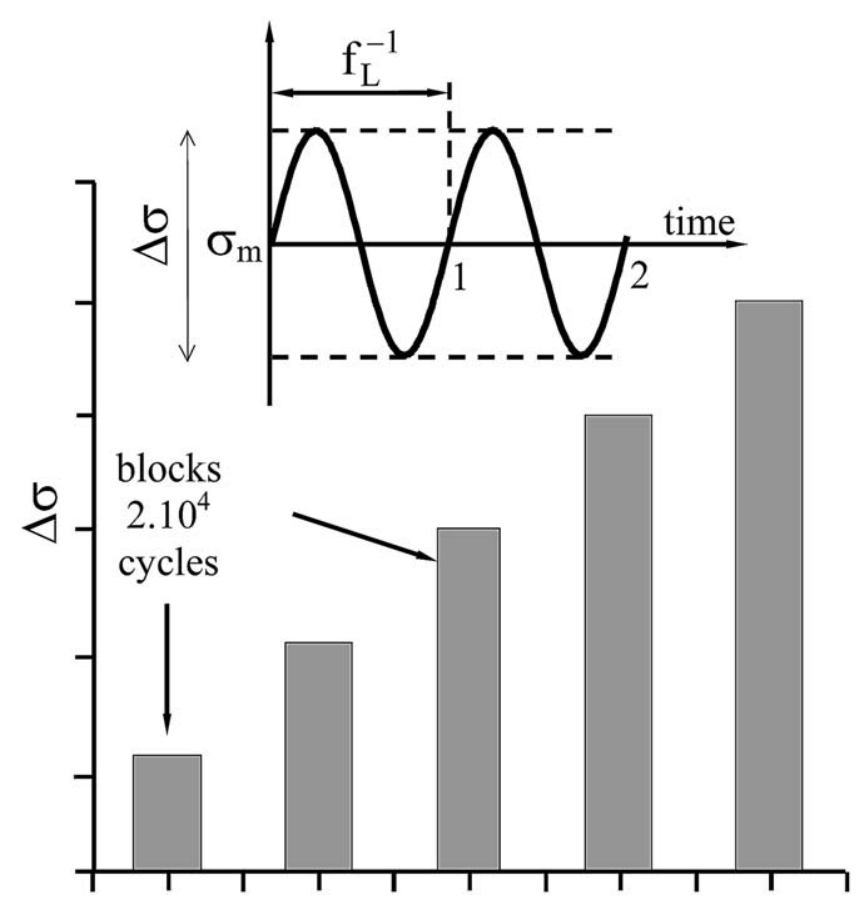

Fig. 1. Basic diagram of the fatigue test. 
$\frac{\mathrm{d} \theta}{\mathrm{d} t}+\frac{\theta}{\tau_{\mathrm{eq}}}=-\frac{\lambda T_{0}}{\rho C} \dot{\sigma}$

For cyclic loading, where

$\sigma(t)=\sigma_{\mathrm{m}}+\frac{\Delta \sigma}{2} \sin \left(2 \pi f_{\mathrm{L}} t\right)$

it is easy to verify that:

- The coupling source is negative during loading and positive during unloading.

- The thermoelastic energy vanishes at the end of each complete loading cycle.

- Solving differential Eq. (10) for such a sinusoidal loading, the periodic part of $\theta_{\text {the }}$ is:

$\theta_{\text {the }}(t)=-\frac{T_{0} \lambda \Delta \sigma}{\rho C} \frac{\pi f_{\mathrm{L}}}{\sqrt{\tau_{\text {eq }}^{-2}+4 \pi^{2} f_{\mathrm{L}}^{2}}} \sin \left(2 \pi f_{\mathrm{L}} t+\varphi\right)$

where $\tan (\varphi)=2 \pi f_{\mathrm{L}} \tau_{\mathrm{eq}}$. Consequently, this temperature variation has the same frequency spectrum as the stress signal and its range during a thermoelastic cycle takes the following form:

$$
\Delta \theta_{\text {the }}=\frac{T_{0} \lambda \Delta \sigma}{\rho C} \frac{2 \pi f_{\mathrm{L}}}{\sqrt{\tau_{\mathrm{eq}}^{-2}+4 \pi^{2} f_{\mathrm{L}}^{2}}}
$$

As expected, Eq. (12) shows that the range $\Delta \theta_{\text {the }}$ vanishes when the loading frequency tends to 0 . Conversely, for high loading frequencies $\left(f_{\mathrm{L}} \gg f_{\mathrm{L}}^{0}=1 / 2 \pi \tau_{\text {eq }}\right)$, the range becomes $f_{\mathrm{L}}$-independent. The time constant $\tau_{\text {eq }}$ can be estimated by exponential regression of the thermal return curves obtained after an elastic loading. Indeed, Eq. (10) implies that return to thermal equilibrium must have an exponential form. Experiments gave us $\tau_{\text {eq }} \approx 80 \mathrm{~s}$, leading to $f_{\mathrm{L}}^{0} \approx 2 \times 10^{-2} \mathrm{~Hz}$. The curve of $\Delta \theta_{\text {the }}$ vs. $f_{\mathrm{L}}$ is plotted in Fig. 2 for a stress range of $\Delta \sigma=360 \mathrm{MPa}$ using Eq. (12).

\subsubsection{Dissipation source}

As the dissipation is always positive, the temperature variation $\theta_{\mathrm{d}}$ induced by $d_{1}$ must be positive according to Eq. (8). Eq. (1) also shows that the dissipated energy may come from both the strain rate $\dot{\varepsilon}$ and $\dot{\alpha}$, which stands for the micro-structural evolution. Some authors have already shown that $\theta_{\mathrm{d}}$ increases with $f_{\mathrm{L}}$ [2]. More precisely, a linear correspondence between $\theta_{\mathrm{d}}$ and $f_{\mathrm{L}}$ was observed in [5]. According to Eq. (8) and for fixed $\Delta \sigma$, the dissipation $d_{1}$ does consequently increase with the strain-rate amplitude.

\section{Experimental results}

In this part, the curves that are presented essentially concern a load ratio $R_{\sigma}=0$. Note, however, that similar

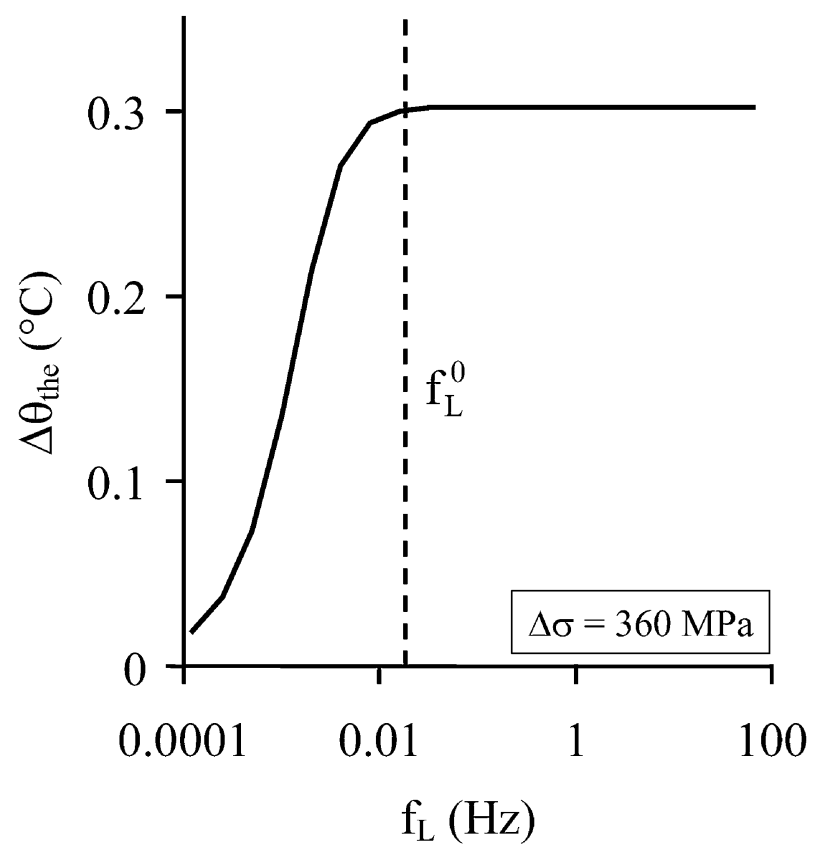

Fig. 2. Temperature range associated with the thermoelastic source as a function of the loading frequency.

results are obtained for a load ratio $R_{\sigma}=0.1$ and $R_{\sigma}=-1$, even though those were not plotted systematically in the following.

\subsection{Thermal effects}

The overall temperature evolution observed during a block at $f_{\mathrm{L}}=50 \mathrm{~Hz}$ is plotted in Fig. 3a. We observed a drift accompanying the thermoelastic response $\theta_{\text {the }}$. We naturally identified this drift as $\theta_{\mathrm{d}}$.

The stabilized shift of $\theta$, denoted $\theta_{\mathrm{d}}^{\text {sta }}$, was interpreted as an effect of a mean dissipation which was regular enough to balance the thermal losses. By comparing these results with those obtained at two other loading frequencies $\left(f_{\mathrm{L}}=1 \mathrm{~Hz}\right.$, Fig. $3 \mathrm{~b} ; f_{\mathrm{L}}=30 \mathrm{~Hz}$, Fig. 3c), we verified that the thermoelastic range $\Delta \theta_{\text {the }}$ was $f_{\mathrm{L}}$-independent. In addition, it is important to note that the experimental value of $\Delta \theta_{\text {the }}$ obtained from these tests at $\Delta \sigma=360 \mathrm{MPa}$ is in very good agreement with the calculated value in Fig. 2 for the same load range $\left(\approx 0.3^{\circ} \mathrm{C}\right)$. Whatever the stress range, the signal is symmetric and periodic at $1 \mathrm{~Hz}$, while drifts accompany the thermoelastic responses at 30 and $50 \mathrm{~Hz}$, and these drifts increase linearly with $f_{\mathrm{L}}$. This latter feature is consistent with experiments shown in [16]. At $1 \mathrm{~Hz}$, we concluded that no drift occurred because of the very low dissipation.

Moreover, the $\theta_{\mathrm{d}}^{\text {sta }}$ also depends on the load range (see Fig. 4). As previously observed by various authors, the relationship between $\theta_{\mathrm{d}}^{\text {sta }}$ and $\Delta \sigma$ is non-linear. This kind of curve, presenting the warming regime of the specimen as a function of the stress range, has been widely used 


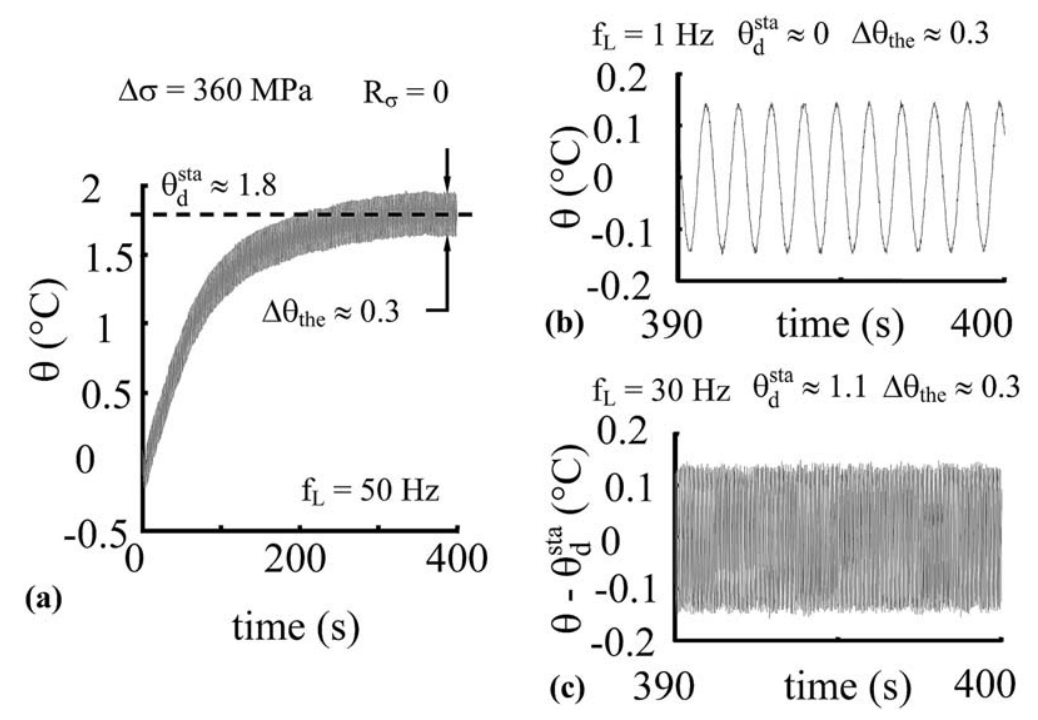

Fig. 3. (a) Whole temperature evolution during a block at $50 \mathrm{~Hz}$; (b) stabilized thermoelastic regime at $1 \mathrm{~Hz}$; (c) stabilized thermoelastic regime at $30 \mathrm{~Hz}$.



Fig. 4. $\theta_{\mathrm{d}}^{\text {sta }}$ vs. $\Delta \sigma$ evolutions for two loading ratios.

to empirically evaluate the fatigue limit of different steels $[1-4,6,16]$.

\subsection{Heat source computation}

Fig. 5 presents the signal processing steps required to determine the intensity of thermoelastic and dissipative heat sources. The first step estimates the overall heat source $s$ using a finite difference approximation of the differential operator of Eq. (8). The loading parameters were $f_{\mathrm{L}}=50 \mathrm{~Hz}, \Delta \sigma=360 \mathrm{MPa}$ and $R_{\sigma}=0$. Because of finite RAM capacity, the sampling frequency was set at $f_{\mathrm{s}}=20 \mathrm{~Hz}$. In such sampling conditions, the thermal signal was too crudely sampled to perform a fine analysis of the thermoelastic sources which are in phase with the loading signal. However, the computation gave an overall source $s$ which seems to be symmetrical and periodic.
This means that the thermoelastic source predominated as compared with the dissipation even though its range was underestimated: $43 \mathrm{~mW} \mathrm{~mm}{ }^{-3}$ (i.e. $12 .{ }^{\circ} \mathrm{C} \mathrm{s}^{-1}$ in Fig. 5) instead of $369 \mathrm{~mW} \mathrm{~mm}{ }^{-3}$ (i.e. $100 .{ }^{\circ} \mathrm{C} \mathrm{s}^{-1}$ in Fig. $6 \mathrm{~b})$ as predicted by thermoelasticity equations.

The second step consists of a time-integration of the overall heat source to get the involved heat $w_{\mathrm{h}}$. This heat was identified as the dissipated energy, with the thermoelastic energy vanishing at the end of each complete cycle.

The results shown in Fig. 5 confirm that $w_{\mathrm{h}}$ increases progressively from cycle to cycle. The slight oscillation of $w_{\mathrm{h}}$ noted here was due to under-sampling. The energy data were locally approximated by straight lines using least-squares fitting. The approximation zone corresponded to around 500 loading cycles. Averaged dissipation $\bar{d}_{1}$ was then estimated by computing the slopes of these fitted straight lines. The results in Fig. 5 show that $\bar{d}_{1}$ is approximately constant throughout the block of cycles at this stress range, but the method does not give any information about instantaneous dissipation within a cycle.

\subsection{Thermoelastic behavior}

Tests were performed at $f_{\mathrm{L}}=1 \mathrm{~Hz}$ to finely analyze the thermoelastic response. Dissipation is negligible and the sampling problems vanish at this loading frequency. To check the consistency of both the thermal diffusion problem (Eq. (8)) and the linear thermoelastic constitutive Eq. (9), we experimentally determined $\Delta \theta_{\text {the }}$ for different $\Delta \sigma$. The results are plotted in Fig. 6a. As predicted by Eq. (12), the relationship between $\Delta \theta_{\text {the }}$ and $\Delta \sigma$ is well fitted by a straight line, even when the specimen was slightly plastically hardened. This is not fully con- 



Fig. 5. From temperature to heat source: data processing.
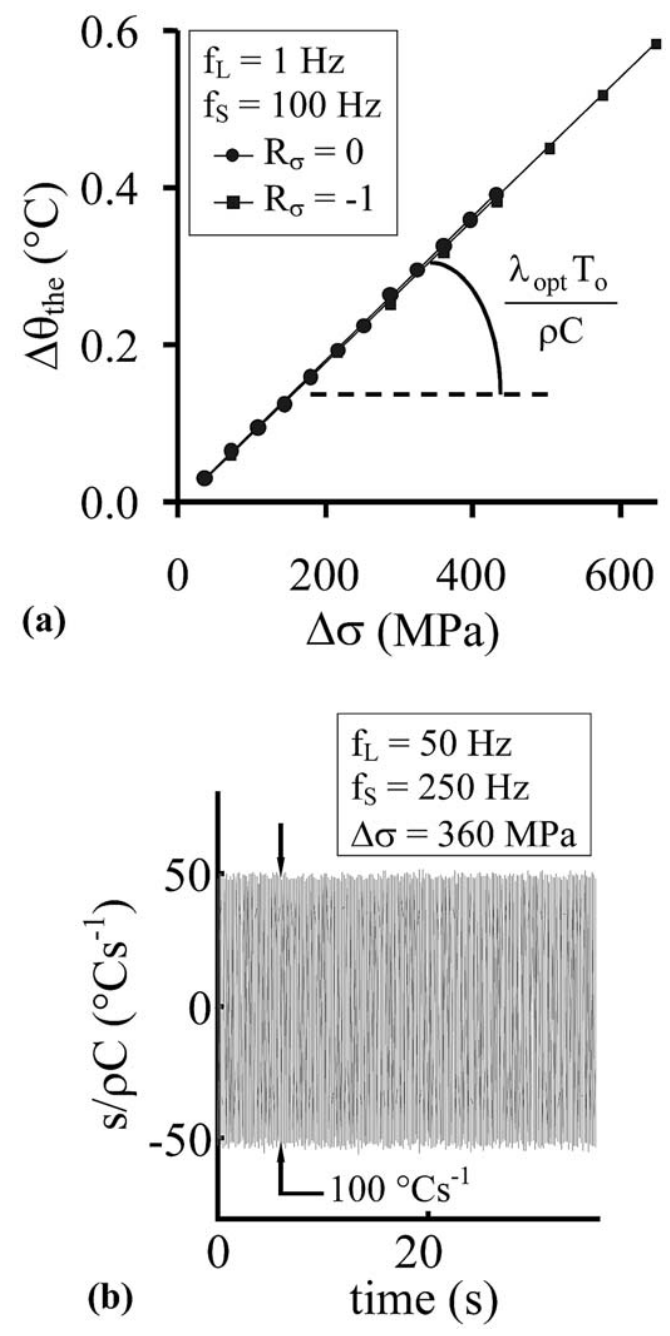

Fig. 6. Thermoelastic data checking: (a) low loading frequency; (b) high loading frequency. sistent with previous tests we performed on other material [17] and with the results obtained by Krapez et al. [4]. Indeed, in these studies, a loss of linearity was observed for a certain load range corresponding to the loss of linearity of $\theta_{\mathrm{d}}^{\text {sta }}$ vs. $\Delta \sigma$. The particular characteristics of DP60, which was especially developed to resist fatigue damage, might account for this different behavior.

Thermoelasticity was also checked at high loading frequencies. Once $\theta_{\mathrm{d}}^{\text {sta }}$ was reached, a burst of images were shot at the highest frame rate $(250 \mathrm{~Hz})$ in order to improve the sampling and consequently the thermoelastic source computation. In Fig. 6b, the data processing gave about $100^{\circ} \mathrm{C} . \mathrm{s}^{-1}$ instead of $103{ }^{\circ} \mathrm{C} . \mathrm{s}^{-1}$ as predicted by Eq. (10). This result is much better than the $12{ }^{\circ} \mathrm{C} . \mathrm{s}^{-1}$ estimated using the under-sampled signal shown in Fig. 5 and highlights that careful temperature signal recording and processing are essential.

In order to assess the possible influence of fatigue on the thermoelastic response, we determined the thermoelastic range for a large number of cycles at high stress range. Fig. 7 shows the evolution of $\Delta \theta_{\text {the }}$ as a function

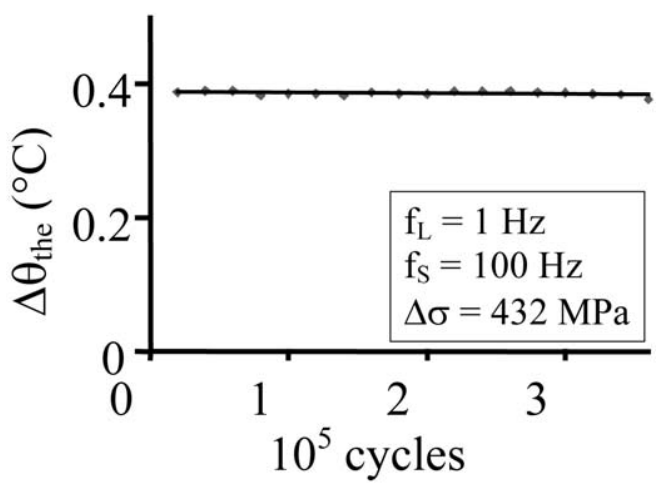

Fig. 7. Evolution of the thermoelastic response during a whole fatigue test. 
of the number of loading cycles. The loading parameters were $\Delta \sigma=432 \mathrm{MPa}, R_{\sigma}=0$. When blocks were performed at $f_{\mathrm{L}}=50 \mathrm{~Hz}$ to maximally reduce test duration, $\Delta \theta_{\text {the }}$ was computed at $f_{\mathrm{L}}=1 \mathrm{~Hz}$. The results in Fig. 7 show that the thermoelastic ranges remained relatively constant until a fatigue crack occurred outside the measurement area at approximately 342,000 cycles.

\subsection{Dissipative behavior}

In Fig. 8, the evolution of $\bar{d}_{1}$ was plotted during blocks performed at increasing stress ranges (increase of $10 \%$ of $R_{\mathrm{p} 0.02}$, i.e. $+36 \mathrm{MPa}$, between blocks) and at constant loading frequency $f_{\mathrm{L}}=50 \mathrm{~Hz}$. This evolution can be split into three stages. At low stress ranges, low dissipation is observed, linearly increasing between blocks. Loss of linearity was reached for about $\Delta \sigma=250 \mathrm{Mpa}$, defining the limit of stage I. Stage II was characterized by dissipation that remained approximately constant during a block. For blocks of stage III, dissipation decreased substantially from an initial value of $\bar{d}_{1}^{\text {ini }}$ to stabilize finally at $\bar{d}_{1}^{\text {sta }}$.

The non-linear evolution of $\bar{d}_{1}^{\text {sta }}$ can be compared with that of $\theta_{\mathrm{d}}^{\text {sta }}$ (Fig. 4) inasmuch as they are proportional during the stabilized regime (see Eq. (8)). As stated before, the curve $\theta_{\mathrm{d}}^{\text {sta }}$ vs. $\Delta \sigma$ was widely used to estimate the fatigue limit. More recently [16], Galtier introduced a stress threshold defined by the inception of slip bands and corresponding to the end of stage I.

In Fig. 8, envelope curves of $\bar{d}_{1}$ were plotted to highlight dissipation scattering during stage III. At least two

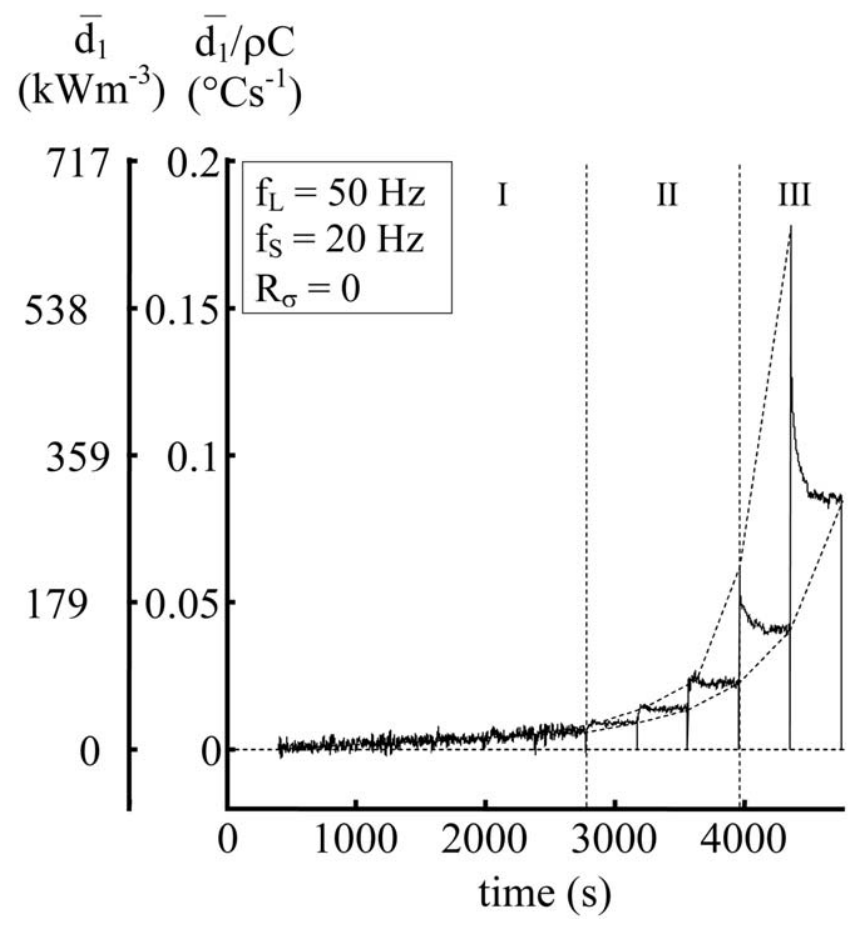

Fig. 8. Dissipation evolution during a block series. interpretations of this property can be put forward. The first conjecture can be formulated in terms of material effects. From this point of view, the strong decrease in dissipation at the beginning of each block can be associated with micro-structure changes leading to material hardening. This can stem from the plasticity effect (the beginning of stage III corresponds to $\sigma_{\max }>R_{\mathrm{p} 0.02}$ in this example) and/or from another phenomenon depending on the load threshold (stage III is also observed for tests conducted at $R_{\sigma}=-1$, before $\sigma_{\text {max }}$ reaches $\left.R_{\mathrm{p} 0.02}\right)$. The second hypothesis concerns structure effects. Remember that dissipation was estimated using Eq. (7). The validity of this equation supposes a uniform distribution of heat sources. So, if a heterogeneous field occurs, the apparently decrease in dissipation may be associated with the transient thermal regime leading to a steady temperature field.

In an attempt to determine which effect is predominant, the test shown in Fig. 8 was extended by four more blocks at constant stress range $(\Delta \sigma=432 \mathrm{MPa})$. The whole test is presented in Fig. 9a. We interpreted the repetitive decreases in dissipation at the beginning of each block as structure effects, assuming that a material effect would lead to a monotonous development of dissipation. This is supported by the fact that a macroscopic fatigue crack occurred at the end of the last block and propagated outside the gauge section (see Fig. 9b). Knowing that the onset of a crack is signaled by strain localization associated with a local heat source [12,18], it would be legitimate to consider that long before the last block (and even for a lower stress range), the heat source field would no longer be homogeneous. In such situations, the chosen data processing strategy is naturally not suitable.

Another data processing approach is thus required to go further in this investigation. As previously shown in Section 3.2, the use of the 1D thermal diffusion Eq. (5) would help to take the non-uniformity of heat sources into account and lead to a more relevant analysis.

\section{Concluding comments}

In this study, the fatigue of DP60 steel was examined in terms of thermal and calorimetric effects. The results regarding the stabilized thermal shift $\theta_{\mathrm{d}}^{\text {sta }}$ were consistent with thermal results in the literature. As regards thermoelastic response $\Delta \theta_{\text {the }}$, the experimental results were also in good agreement with theoretical estimates. Considering the calorimetric effects, data processing based on a simplified heat equation enabled us to separately estimate the dissipative and thermoelastic sources. The method allowed us to observe very low dissipation intensities compared to thermoelastic source amplitudes. Despite its weakness, we showed that dissipation depends on the loading frequency and on the stress range 

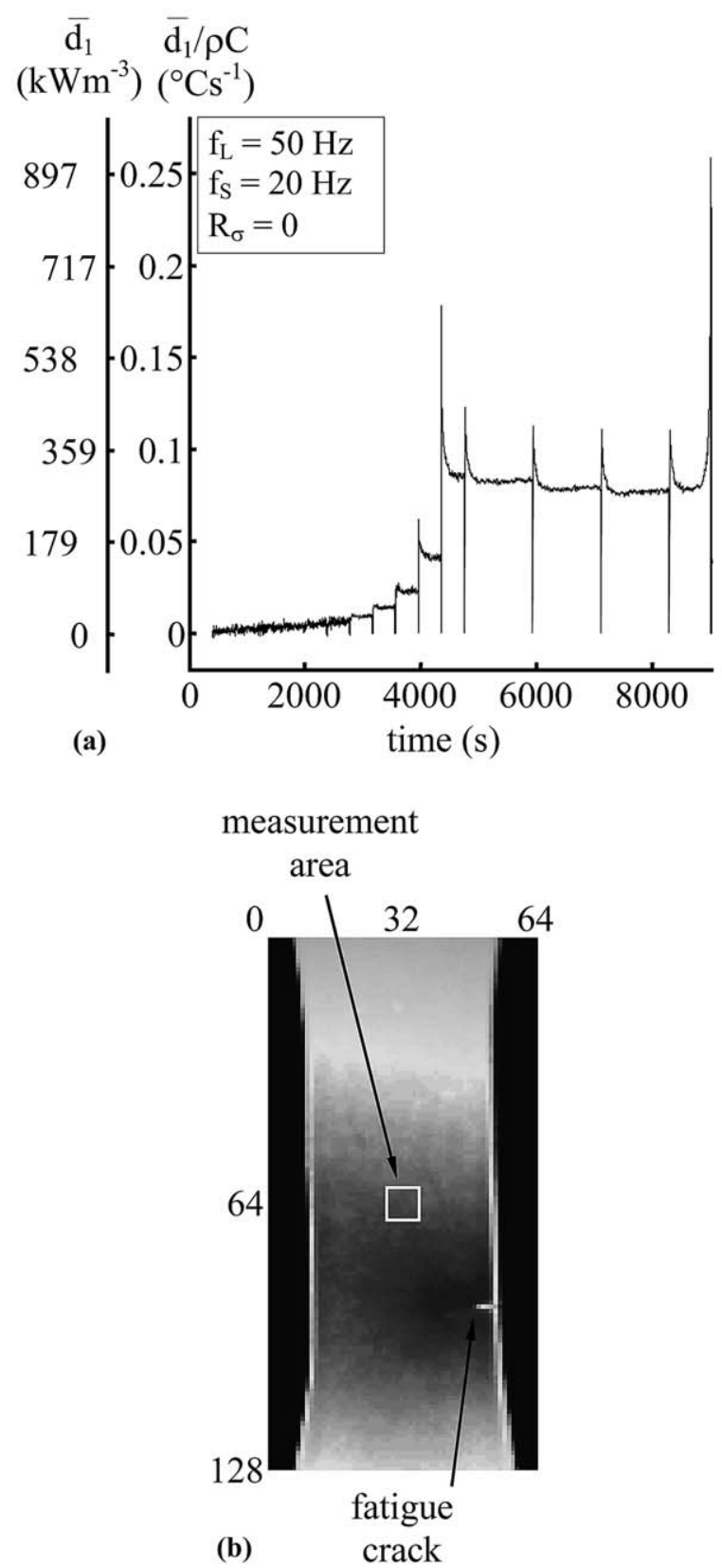

Fig. 9. (a) Evolution of the mean dissipation until crack onset. (b) Temperature field during crack propagation.

applied to the fatigue specimen. All the calculations were performed under a strong hypothesis: the uniformity of heat sources induced by a homogeneous fatigue test. Decreases in dissipation observed at the beginning of each block associated with a high stress range indicated that the heat source fields were non-uniform. Use of the $1 \mathrm{D}$ thermal diffusion equation for data processing is therefore essential to partially take structure effects into account and generate more reliable dissipation values. If an early heterogeneous development of dissipation mechanisms is confirmed, the fatigue limits ident- ified on the basis of $\theta_{\mathrm{d}}^{\text {sta }}$ data will have to be correlated to the heat source distribution.

\section{References}

[1] Luong MP. Fatigue limit evaluation of metals using an infrared thermographic technique. Mechanics of Materials 1998;28:15563.

[2] La Rosa G, Risitano A. Thermographic methodology for rapid determination of the fatigue limit of materials and mechanical components. International Journal of Fatigue 2000;22:65-73.

[3] Yang B, Liaw PK, Wang H, Jiang L, Huang JY, Kuo RC, et al. Thermographic investigation of the fatigue behavior of reactor pressure vessel steels. Materials Science and Engineering A 2001;314:131-9.

[4] Krapez JC, Pacou D, Gardette G. Lock-in thermography and fatigue limit of metals. Quantitative infrared thermography 5. In: Balageas D, Beaudoin JL, Busse G, Carlomagno GM, editors. QIRT' 2000. Lodz, Poland: Akademickie Centrum GraficznoMarketingowe Lodart S.A.; 2000. p. 277-282.

[5] Galtier A. Contribution à l'étude de l'endommagement des aciers sous sollicitations uni ou multi-axiales. Phd thesis, ENSAM Bordeaux, 1993.

[6] Morabito AE, Dattoma V, Galietti U. Energy-analysis of fatigue damage by thermographic technique. In: Maldague XP, Rozlosnick AE, editors. XXIV Thermosense Conference, vol. 4710. SPIE; 2002. p. 460-7.

[7] Jiang L, Brooks CR, Liaw PK, Wang H, Rawn Claudia J, Klarstrom DL. High-frequency metal fatigue: the high-cycle fatigue behavior of ULTIMET(R) alloy. Materials Science and Engineering A 2001;314:162-75.

[8] Louche H, Chrysochoos A. Thermal and dissipative effects accompanying Luders band propagation. Materials Science and Engineering A 2001;307:15-22.

[9] Balandraud X, Chrysochoos A, Leclercq S, Peyroux R. Influence of the thermomechanical coupling on the propagation of a phase change front. Comptes Rendus de l'Academie des Sciences-Series IIB-Mechanics 2001;329:621-6.

[10] Germain P, Nguyen QS, Suquet P. Continuum thermodynamics. Journal of Applied Mechanics 1983;50:1010-20.

[11] Lemaitre J, Chaboche JL. Mechanics of solid materials. Cambridge University Press; 1990.

[12] Chrysochoos A, Louche H. An infrared image processing to analyse the calorific effects accompanying strain localisation. International Journal of Engineering Science 2000;38:1759-88.

[13] Capatina A, Stavre R. Algorithms and convergence results for an inverse problem in heat propagation. International Journal of Engineering Science 2000;38:575-87.

[14] Chrysochoos A, Muracciole JM, Wattrisse B. Experimental analysis of strain and damage localization. In: Continuous damage and fracture. Elsevier; 2000. p. 41-51.

[15] http://www.usinorauto.com/v_anglaise/produits/fiches/a_usiphased 1.htm

[16] Cugy P, Galtier A. Microplasticity and temperature increase in low carbon steels. Fatigue 2002 2002;:549-56.

[17] Mabru C, Chrysochoos A. Dissipation et couplages accompagnant la fatigue de matériaux métalliques. In: Berthaud Y, Cottron M, Dupré J-C, Morestin F, Orteu J-J, Valle V, editors. Photomecanique 2001. GAMAC; 2001. p. 375-82.

[18] Wattrisse B, Chrysochoos A, Muracciole J-M, Nemoz-Gaillard M. Kinematic manifestations of localisation phenomena in steels by digital image correlation. European Journal of MechanicsA/Solids 2001;20:189-211. 